\title{
Public acceptance in financing urban transportation projects using the Value Capture concept
}

\author{
S. Basbas, G. Mintsis, C. Taxiltaris, A. Roukouni \& A. Vazakidis \\ Faculty of Rural and Surveying Engineering, \\ Aristotle University of Thessaloniki, Greece
}

\begin{abstract}
The need for transportation infrastructure and services continuously increases in urban areas worldwide but at the same time the availability of public resources is shrinking. This paper refers to the potential use of alternative financing strategies for transportation infrastructure, which are based on the Value Capture Finance (VCF) concept. A factor which has a significant role in the potential success or failure of VCF implementation is public acceptance. The objective of the present paper is thus to examine the potential introduction of a VCF for the financing of Thessaloniki's metro system in Greece. More specifically, a questionnaire-based survey was conducted, focusing on the public acceptance factor. The case study is the area around a central metro station, located in the heart of the urban complex. The research presented is based on a questionnaire-based survey which took place in spring 2014 and was addressed to visitors of the area around the planned metro station. The majority of the survey's participants consider that the urban environment is very likely to be upgraded due to the enhancement of accessibility as an effect of the new metro station. Nevertheless, the public's enthusiasm is reduced significantly when the discussion reaches their willingness to pay in order to cover a part of the project's construction cost.
\end{abstract}

Keywords: Value Capture Finance, questionnaire-based survey, public acceptance, urban public transport

\section{Introduction}

The complexity of modern urban needs continuously increases as more and more people move to cities worldwide. In an increasingly urbanized world, innovative 
solutions are required, linked with the three pillars of sustainability: society, economy and the environment. An essential component for the success of every urban system is an extensive robust public transport network. However, due to the limited public resources as a consequence of the global financial crisis there is a considerable lack of funding dedicated to large-scale urban projects. A very promising source of revenue that has gained much attention especially during the last years due to the aforementioned conditions is the family of Value Capture Financing (VCF) mechanisms.

In this context, the present paper suggests a methodological approach of examining a very critical factor of success when the introduction of a VCF mechanism is considered: the public perception which refers to the degree of acceptance by the citizens. The methodology includes the preparation, design and distribution of a questionnaire addressed to citizens (pedestrians around a planned central metro station). The case study is the Thessaloniki metro project, an on-going project the construction of which has started in 2006. It must be mentioned at this point that Thessaloniki is the second biggest urban agglomeration (after Athens) in Greece. After its completion, the basic metro line will run for $9.6 \mathrm{~km}$ through the city, having 13 stations. The objective of this paper is to capture and analyse the views and perceptions of the citizens concerning a potential implementation of a VCF tool for the metro.

\section{Literature review}

The topic of investigating the relationship between new or improved transportation infrastructure (and thus enhanced accessibility) and property values has been extensively covered by numerous research studies worldwide, most of which have shown the existence of a strong positive relationship, assuming that all else are being equal (e.g. see [1-6]).

Therefore, a public transportation project could be beneficial not only for its users but also for the property owners whose properties are located nearby and their value grows as well as for the business owners who experience an increase in customers and revenue due to the increased accessibility. This group of people is often called the "indirect beneficiaries" of the project [7]. The VCF mechanisms are targeted mainly to this group and are based on the so-called "benefit principle" according to which whoever benefits from an infrastructure or service should pay for it [8]. The basic notion of VCF is thus that part of the cost of an investment in public infrastructure could be recovered by capturing a percentage the rise in value that results from the investment. The value increment could also be used to reinvest in the area. Many variations of VCF tools exist and there are several applications worldwide. For a comprehensive annotated bibliography (see Smith et al. [9]). Regarding mass transit system, Medda [10] has categorized them in three main groups: Betterment tax, Accessibility Increment Contribution and Joint Development. The research presented herein focuses on the first one, the betterment tax, a special tax that is levied to properties which benefit from the increased accessibility. 
The essential role of public acceptance for the successful implementation of any VCF mechanism is emphasized by Walters [11]. According to him, prerequisites for this acceptance is the existence of fair and transparent administration and citizens' involvement in critical decision -making. Public acceptance is also one of the criteria used by Litman [12] in his evaluation of 18 different possible financing mechanisms for public transportation infrastructure. Moreover, Doherty [13] points out the importance that the authority provides the citizens with clear and explicit information concerning the necessity of a VCF mechanism, before its introduction and also believes that the mechanism has increased chances to succeed in case its implementation is accompanied with reliefs to the general existing taxation.

As reported by Greenleaf Strategies LLC and Parsons Brinckerhoff [14], in case of VCF mechanisms, the absence of support of private property owners could threaten the feasibility of the whole project, due to the fact that a significant funding source of it would shrink dramatically. Therefore, citizens' support can even be the crucial factor of success or not of the project. The Committee for Melbourne [15] ends "Moving Melbourne", a transport funding and financing discussion paper focused on the potential introduction of alternative mechanisms like VCF, by rhetorically asking the community of Melbourne whether the citizens would be prepared to accelerate improvements at a location of level crossing and similar locations by contributing to the funding and in case they are, if they are prepared to do so by a special levy on surrounding ratepayers. McIntosh et al. [16], investigated the willingness to pay for transit access in Perth, Western Australia, by the use of cross-sectional and panel data hedonic price modelling methodology, which belongs to the family of revealed preference methods for estimating willingness to pay. Their research concluded that there is a noteworthy attractiveness of living near transit stations, even in car-dependent cities like Perth, and hence the potential for value capture is robust.

\section{Survey design and methodology}

In order to investigate the public perception towards the potential introduction of a financing tool based on the VCF concept to partially finance the Thessaloniki Metro project, a questionnaire survey was designed and addressed to the citizens.

The questionnaire is divided in three parts. The first part attempts to outline the socio-economic profile of the persons included in the survey, by recording characteristics such as their gender, age group, occupation, educational level, salary level etc. The second part examines the mobility patterns of the participants, focusing on the specific trip during which the survey took place (origin-destination, trip purpose, means of transport used etc.). Finally, the last part aims to capture the interviewee's perception of the economic impact of the new metro line on the surrounding properties and most importantly, his/her willingness to contribute to the financing of the line through a special tax/tariff (which is based on the VCF notion). 
Table 1: Questionnaire - variables, coding and classification.

\begin{tabular}{|c|c|c|}
\hline Code & Variable & Classification \\
\hline A1 & Gender & Man, woman \\
\hline A2 & Age & $18-24,25-34,35-44,45-54,55-64,>=65$ \\
\hline A3 & Occupation & $\begin{array}{l}\text { Scientists and professionals, staff and officials, tradesmen } \\
\text { and sales workers, service workers, craftsmen and labourers, } \\
\text { unemployed, students, retired, housewives }\end{array}$ \\
\hline A4 & $\begin{array}{l}\text { Average monthly household } \\
\text { income }\end{array}$ & $0,<500,501-800,801-1500,1500-2500,>2.500(€)$ \\
\hline A5 & Educational level & Primary, secondary, student, higher, university degree \\
\hline A6 & Home area & $\begin{array}{l}\text { City Centre, Eastern Thessaloniki, Western Thessaloniki, } \\
\text { Outside Thessaloniki. }\end{array}$ \\
\hline A7 & Work area & $\begin{array}{l}\text { City Centre, Eastern Thessaloniki, Western Thessaloniki, } \\
\text { Outside Thessaloniki. }\end{array}$ \\
\hline B1 & Trip purpose & Work, education, leisure, shopping, other, combination \\
\hline B2 & Transport mode & $\begin{array}{l}\text { Car as driver, car as fellow passenger, bus, taxi, motorcycle, } \\
\text { bicycle, pedestrian, combination of modes }\end{array}$ \\
\hline B3 & Frequency of use & Yes, no \\
\hline B4 & Frequency of visits to this area & Every day, 3-4 times a week, once a week, rarely, first time \\
\hline C1 & $\begin{array}{l}\text { Would you use the metro for } \\
\text { this trip? }\end{array}$ & $\begin{array}{l}\text { Yes/Probably Yes, I do not know/I would prefer not to } \\
\text { answer this question, No/Probably No }\end{array}$ \\
\hline C1i & If yes, for which reason mainly? & $\begin{array}{l}\text { Speed, convenience, easy access to destination, save money, } \\
\text { other }\end{array}$ \\
\hline C2 & $\begin{array}{l}\text { Will the properties around } \\
\text { metro stations experience an } \\
\text { increase in the value after the } \\
\text { operation of the line? }\end{array}$ & $\begin{array}{l}\text { Yes/Probably Yes, I do not know/I would prefer not to } \\
\text { answer this question, No/Probably No }\end{array}$ \\
\hline $\mathrm{C} 2 \mathrm{i}$ & If yes, estimate this increase & $0-10 \%, 11-25 \%, 26-40 \%, 41-50 \%$ \\
\hline $\mathrm{C} 3$ & $\begin{array}{l}\text { Will the quality of life and } \\
\text { urban environment around the } \\
\text { stations be upgraded? }\end{array}$ & $\begin{array}{l}\text { Yes/Probably Yes, I do not know/I would prefer not to } \\
\text { answer this question, No/Probably No }\end{array}$ \\
\hline $\mathrm{C} 3 \mathrm{i}$ & If yes, how much? & Very little, Little, Medium, Much, Considerably \\
\hline C4 & $\begin{array}{l}\text { Would you be positive against } \\
\text { the potential to contribute to the } \\
\text { financing of the metro through a } \\
\text { new special tax/tariff? }\end{array}$ & $\begin{array}{l}\text { Yes/Probably Yes, I do not know/I would prefer not to } \\
\text { answer this question, No/Probably No }\end{array}$ \\
\hline $\mathrm{C} 4 \mathrm{i}$ & If yes, for which reason mainly? & $\begin{array}{l}\text { Faster project completion, better quality of service, benefits } \\
\text { from increased accessibility, increased property value, } \\
\text { facilitation of your trips, other }\end{array}$ \\
\hline C4ii & $\begin{array}{l}\text { What \% of your home or work } \\
\text { property value would you } \\
\text { dedicate for this tax? }\end{array}$ & $0.25-1.00 \%, 1.00-2.00 \%,>2.00 \%$, other \\
\hline C4iii & $\begin{array}{l}\text { Do you think those who } \\
\text { live/work at areas close to } \\
\text { stations ought to pay more than } \\
\text { those of more distant areas? }\end{array}$ & $\begin{array}{l}\text { Yes/Probably Yes, I do not know/I would prefer not to } \\
\text { answer this question, No/Probably No }\end{array}$ \\
\hline C5 & $\begin{array}{l}\text { If you are negative towards the } \\
\text { idea of contributing to the } \\
\text { financing of the metro line, } \\
\text { which are the main reasons for } \\
\text { that? }\end{array}$ & $\begin{array}{l}\text { Existing taxation, economic crisis, transportation } \\
\text { infrastructure is government's responsibility, money may not } \\
\text { be utilised for this purpose, other }\end{array}$ \\
\hline C6 & $\begin{array}{l}\text { When would you prefer to pay } \\
\text { the tax? }\end{array}$ & $\begin{array}{l}\text { After project completion, during construction phase, I do not } \\
\text { know/I would prefer not to answer this question }\end{array}$ \\
\hline C7 & $\begin{array}{l}\text { Which do you think would be } \\
\text { the best way in order for to } \\
\text { citizens to be familiarised with } \\
\text { such a financing mechanism? }\end{array}$ & $\begin{array}{l}\text { Advertisements/marketing campaign, Public consultation } \\
\text { with stakeholders' participation, Integration to central } \\
\text { policies, Other, I do not know/I prefer not to answer this } \\
\text { question }\end{array}$ \\
\hline
\end{tabular}


The majority of the questions that were chosen to be included in the questionnaire are close-ended, which means that the interviewee is invited to choose among given answers, the one(s) which she/he considers more close to her/his view on the topic. Nevertheless, it was considered necessary to include some open-ended questions as well, and at some close-ended ones the interviewees are given the opportunity to add their own answer in case none of the existing ones do fully express their opinion. The predefined answer boxes in some cases cover a range of potential answers while in other cases, especially in the SP part, they indicate the degree of agreement with the statement. The answers to the open questions were afterwards grouped and coded in order to facilitate their analysis. The coding was based on the official coding suggested by the Hellenic Statistical Authority (EL.STAT.), after making the necessary changes and adaptations. The description of the chosen variables, their coding and classification are presented in Table 1.

\section{Case study area and data collection}

The chosen case study includes the area around Agia Sofia planned metro station, situated in the heart of the urban complex of Thessaloniki. Agia Sofia Street crosses the area of the homonymous byzantine church - one of Thessaloniki's landmarks - and is one of the busiest streets of the city centre, characterised by the presence of mainly commercial and business land use. After a pilot phase of temporary pedestrianisation which lasted for the few last years, a complete redevelopment study has been conducted, which among others suggests the permanent pedestrianisation of the Agia Sofia axis.

The questionnaire-based survey took place in late March 2014 [17] on typical weekdays, by direct personal interviews to pedestrians. This method was chosen aiming to avoid missing values and misinterpretation of the questions.

In order to test the effectiveness of the designed questionnaire and discover potential errors or/and ambiguities, initially a pilot survey took place at the area, during which 30 questionnaires were completed. Participants were encouraged to comment on the questionnaire's structure and content as well as indicate whether they confronted any difficulties in comprehending the questions. No significant problems were reported; only minor typographical mistakes and omissions, which were corrected accordingly. The main survey followed; it was applied to a random sampling of pedestrians within the case study area which was previously described. Totally, 300 valid questionnaires were collected.

\section{Results and discussion}

The collected data were imported in a database and the descriptive statistical analysis of all the variables took place in order to calculate the frequencies with which each variable appears in the sample and to reach to conclusions. Pie charts and bar charts were formed in order to illustrate these results. 


\subsection{Part A: socio-economic characteristics}

The women participants in the survey are slightly more than men (60\%). Figure 1(a) presents the age groups of the interviewees. The majority of them are between 18 and 24 years old (37\%), while the age group 25-34 follows with almost $30 \%$. This is not a surprise as with the existence of two large Universities within the city centre, Thessaloniki is a youth attraction pole. The pie chart reveals that the participation in the survey decreases as age increases, with the elderly representing only approximately $4 \%$ of the sample. The occupation profile of the participants (Figure 1(b)) is in line with their age profile, as the percentage of those who claimed to be students almost coincides with the first age group (32\%). Almost one out of five $(20.3 \%)$ is scientist or professional (self-employed), category which is followed by the one of staff and officials with $17 \%$. The percentage of unemployed persons $(10 \%)$ is also noteworthy - yet not unexpected, taking into account the consequences of the economic crisis and the austerity policies that have been implemented to Greece during the last years. Concerning their monthly average household income, the majority of participants answered that it ranges between 801 and $1500 €(35 \%)$. Almost equal (around 20\%) is the participation in the sample of persons with household income $500-800 €$ as well as $1501-2500 €$. For a $12.3 \%$ of the participants, the monthly income does not exceed the amount of $500 €$.

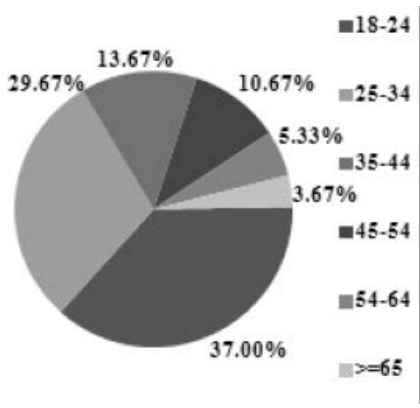

(a)

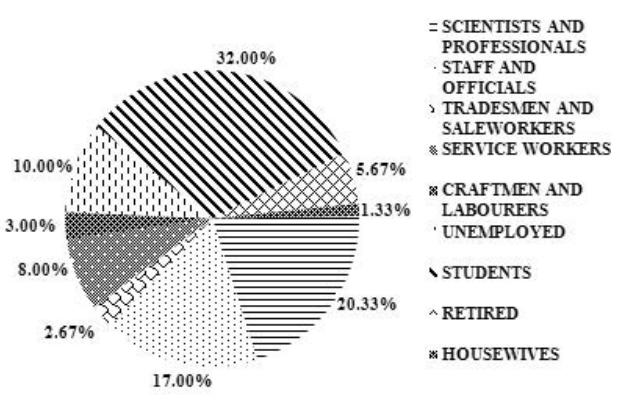

(b)

Figure 1: (a) Age groups; (b) occupation.

Nevertheless, there is also a 10.6\% with income above the threshold of $2500 €$ while only $2.3 \%$ have zero average household income (Figure 2(a)). The discrepancy between this low figure and the corresponding high percentage of unemployed persons as presented in the pie chart above can be explained due to the fact that this question aims to examine the economic state of the household. Rationally, the financial decisions a person makes are usually affected by the household she/he belongs to.

Figure 2(b) illustrates the educational level of the survey's sample. Almost half of them $(46 \%)$ hold a university degree, while students comprise a significant percentage $(32.7 \%)$ as well. Interviewees who have only completed primary education form a minority, with their percentage limited to a $3.3 \%$. 
Hence, most of the citizens that participated to the survey have received or are currently receiving higher/university education. Most of the persons undertaken the survey are residents of the centre of Thessaloniki. The same figure reveals that only a $9.3 \%$ lives permanently outside the city, while the rest are almost equivalently allocated between the eastern and western part of Thessaloniki. Regarding the work area, the city centre raises its percentage reaching $67.2 \%$, while Eastern Thessaloniki follows with a $12.8 \%$, a little higher than the $9.2 \%$ of Western Thessaloniki.

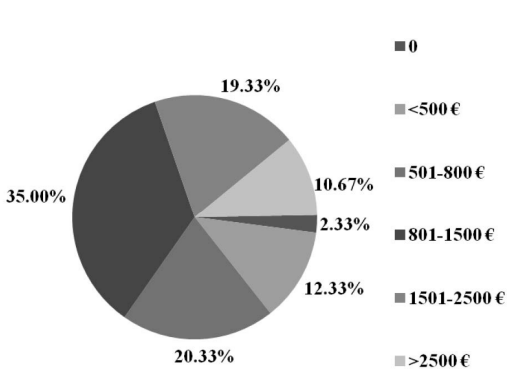

(a)

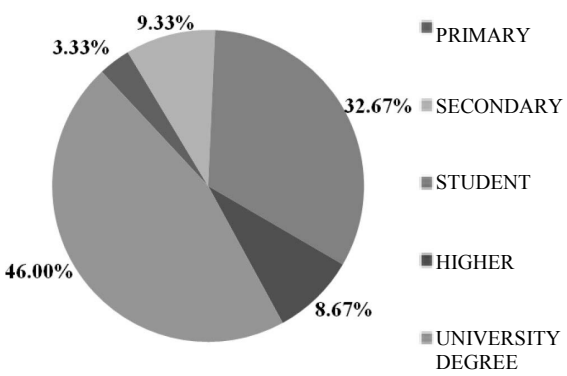

(b)

Figure 2: (a) Average monthly household income; (b) educational level.

\subsection{Part B: mobility patterns}

Most of the survey's participants stated leisure as the purpose of their specific trip $(42.7 \%)$ while one out of four completed the questionnaire on their way to/from work. Regardless the large participation of students in the sample population, only an $8.3 \%$ said that their trip took place due to educational reasons. There was also a $6.7 \%$ whose trip purpose comprised more than one from the aforementioned choices (Figure 3(a)). Figure 3(b) presents the transport mode(s) used for their trip. The majority were pedestrians $(43.3 \%)$ whilst the percentage of those taking the bus was also important (37.7\%). A rather low percentage (11\%) used their private cars (either as drivers or fellow passengers) and a $7 \%$ preferred a combination of modes.

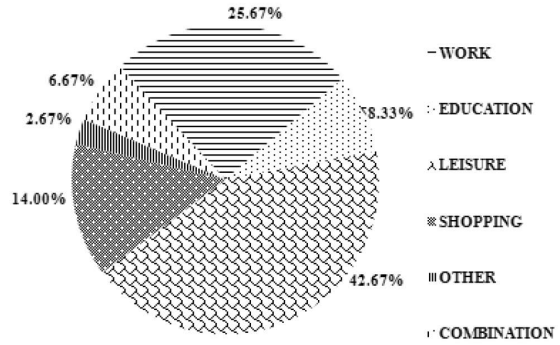

(a)

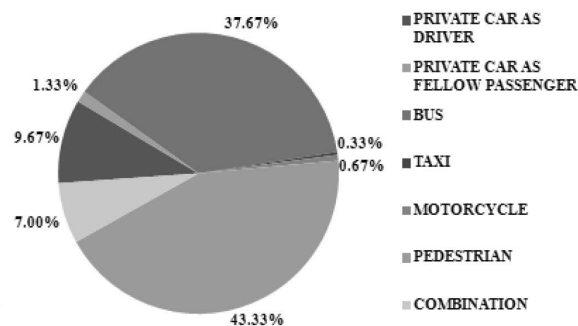

(b)

Figure 3: (a) Trip purpose; (b) mode of transport use. 
It is surprising that not a single one of the participants used a bicycle. A great majority $(81 \%)$ stated that the transport mode they used for that specific trip was actually the mode they usually prefer for travelling within the city boundaries. Regarding the frequency of visiting the area, approximately $65 \%$ admitted to spend visits there rather frequently (every day or 3-4 times a week). The rest claimed to usually cross the area once a week or even rarely, while only one person found her/himself there for the very first time.

\subsection{Part C: stated preferences}

This part of the questionnaire attempts to decode their views towards the future operation of the metro line and its potential impact to the area as well as to reveal how they feel about the potential of financing part of the line using a mechanism based on the VCF concept. Initially, most of the interviewees $(59 \%)$ react positively to the thought of using the metro instead of the mode they had used for that specific trip. The number of positive answers increases even further when the question of whether the properties around the planned metro stations will experience a raise in value is posed, with a remarkable $82 \%$ choosing "Yes/Probably yes". Noticeable is also the fact that most of them by far $(65.3 \%)$ believe that the area will be upgraded both in terms of quality of life and urban environment when the metro line becomes fully operative. Nevertheless, this positive climate is all of a sudden reversed when the VCF concept is introduced in the discussion. The question about whether they are willing to contribute financially by a special tax/tariff to the metro financing process gets a resounding "No/Probably no" (80\%) (Figure 4). Those who said that they would take the metro if it was an available alternative for this trip were afterwards asked to justify their answer by stating the main reason for doing so. Increased speed appears to be by far their primary incentive $(69 \%)$, followed by facilitation of access to their preferred destination (13\%) and perceived convenience $(8 \%)$,

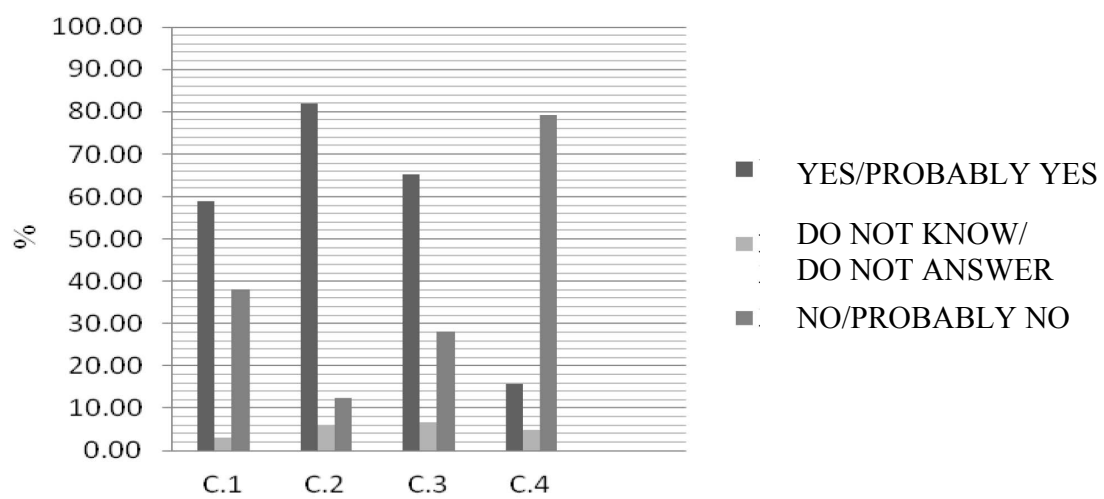

Figure 4: Intense differentiation of answers between the first three SP questions and the fourth which focuses on VCF. 
while money saving and safety do not seem so important to many (Figure 5(a)). The majority of those who claimed that an increase in value of surrounding properties is a very probable future scenario argued that this boost will range between an additional 11 and $25 \%$ comparing to their current value. Approximately one quarter of them foresaw an even further growth of $26-40 \%$, while the rest $28 \%$ is almost equally shared between those who estimate a value increment only up to $+10 \%$ and those who suggest a higher increment that could reach even the $50 \%$ of the current properties' value (Figure 5(b)).

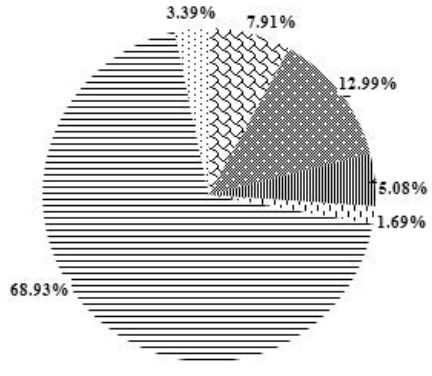

(a)
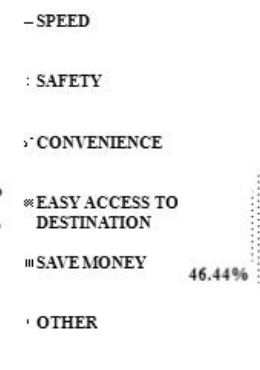

(b)

Figure 5: (a) Main reason for choosing the metro; (b) estimation of value increment due to the metro line.

Regarding the urban renewal and improvements on the quality of life, the interviewees who replied positively, mainly think that the change will be significant, followed by a $34 \%$ that estimate a more mediocre degree of amelioration, whilst $24 \%$ expect little improvements and only $3.6 \%$ considerable transformation of the area. The little percentage of survey participants that was positive towards a potential introduction of a VCF tool was then asked to state the main reason that would lead them to that choice (Figure 6(a)). In other words the interviewees were encouraged to argue what expectations they would have by contributing to the financing. Most of them answered that they would expect the facilitation of their daily trips (40.4\%) and a $25.5 \%$ considered the provision of better service quality as a motive to do so. The view that the project would be completed faster if they contribute to its financing was expressed by a $21.3 \%$, whilst a few think that as they will benefit from the increased accessibility, they are willing to pay for it. It is worth noticing though, that not even one person chose the answer "Due to increased property value". Therefore, it is not such a surprise to read the answers to the question: "What percentage of your home or work property value would you dedicate for this tax?". The great majority $(80.9 \%)$ said that the tax should be limited to the $0.5-1 \%$ of the estimated value of their property and there is an approximately $19 \%$ who would pay a little more, between $1-2 \%$. Nobody is willing to give a higher contribution. Moreover, $75 \%$ consider that the properties located closer to a metro station should not pay more than those who situated far away from the stations. Hence, they do not seem to support, at least initially, a distance based approach. 
Another important question is the one which was addressed to the (numerous) opponents of the VCF idea and attempted to investigate the reasons why they are negative to it. Most of them (46.6\%) appeared to have the perception that the construction and provision of transportation infrastructure should be exclusively government's responsibility and they cannot see why they should be directly involved in such a process. A critical part of the responders $(22 \%)$ expressed distrust on whether the potential contribution would be indeed used for its intending purpose whilst $16.8 \%$ think that they already pay a lot of taxes and hence they would be unable to cope with another one. Finally, the economic crisis and its consequences seems to be the principal reason to be against a VCF policy for an $8.1 \%$ (Figure 6(b)).

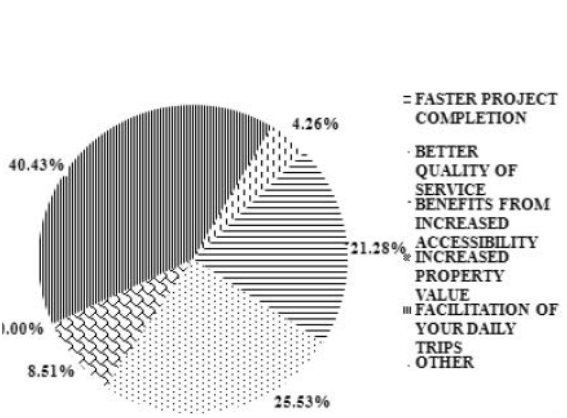

(a)

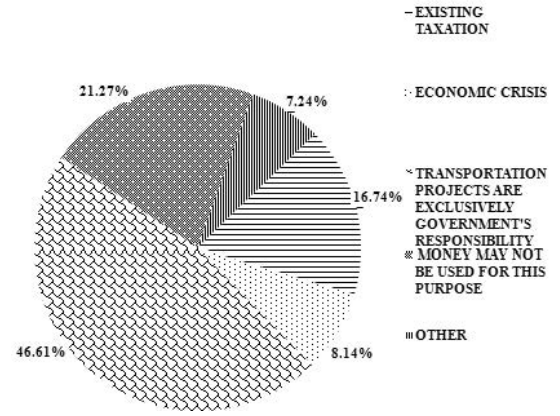

(b)

Figure 6: (a) Main reason for contributing to the financing through a VCF tax; (b) main reason not to do so.

Concerning the implementation timing of the potential measure, around half of the interviewees would prefer it after the completion of the construction and an approximately $30 \%$ argues that during the construction phase would be preferable. The $\%$ of those who are not sure or would prefer not to answer this specific question is also relatively high though (Figure 7(a)). The last question is

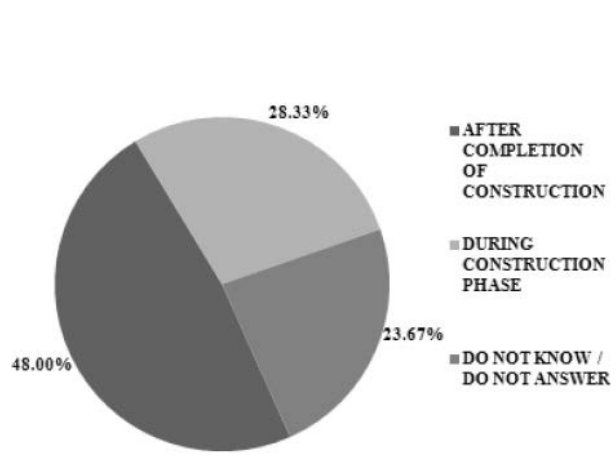

(a)

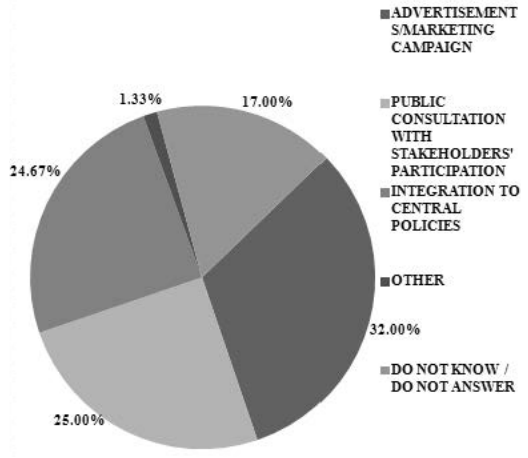

(b)

Figure 7: (a) Optimum timing for VCF implementation; (b) optimum way of citizens' familiarization with VCF. 
a rather important one due to the fact that it aims to investigate which would be the optimum way to familiarize the citizens with this kind of financing mechanisms.

The answers obtained lie in three groups. The first group - which has a relative predominance with $32 \%$ - considers that a targeted marketing campaign would have a good chance of getting them familiarized with the VCF concept. The second and the third group involve approximately $25 \%$ of the survey participants each. The former chose the "public consultation with stakeholders' participation" option as their preferable way while the latter is positive towards the idea of incorporation of such a concept to a central policy framework and its step by step implementation to different transportation projects (Figure 7(b)).

\section{Conclusions}

The present paper suggests an approach of how to capture the public's views and perceptions towards different ways of financing urban public transportation projects. As far as the international experience is concerned, it must be noted that in cases when citizens are involved through various methods and processes in early stages of decision making regarding urban project financing, this results mainly to positive public reaction when a VCF mechanism is under discussion. This especially refers to cities and regions with well-established procedures in this direction. The novel aspect of this paper is the fact that it introduces the discussion of how acceptable a financing tool based on the VCF notion for urban transport would be by the citizens, in an era of economic crisis, especially in European cities of the South, by taking into account the case study of Thessaloniki. Most citizens consider that new/improved transportation infrastructure and associated enhanced accessibility would have a very positive impact on urban quality of living and property values of surrounding areas; however, the vast majority of them is strongly opposed to a potential monetary contribution to the project. This can be explained by the fact that during the last years Greek citizens have experienced the implementation of a series of austerity measures. The results from the Thessaloniki case study indicate that the VCF concept is yet outside the Greek mentality and important steps towards this direction have still to be taken. Ideas for future research include further analysis of the data presented herein, with the use of regression statistical modeling and possibly multivariable statistical analysis in order to reveal correlations among variables which are not obvious or easily perceived.

\section{References}

[1] Cervero, R. \& Landis, J., Assessing the impacts of urban rail transit on local real estate markets using quasi-experimental comparisons. Transportation Research Part A: Policy and Practice, 27, pp. 13-22, 1993. 
[2] Cervero, R. \& Duncan, M., Benefits of proximity to rail on housing markets: experiences in Santa Clara County. Journal of public transportation, 5(1), pp. 1-18, 2002.

[3] Bowes, D.R. \& Ihlanfeldt, K.R., Identifying the Impacts of Rail Transit Stations on Property Values. Journal of Urban Economics, 50, pp. 1-25, 2001.

[4] Brinkerhoff P., The Effects of Rail Transit on Property Values: A Summary of Studies, Project 21439S, Task 7, NEORail II, Cleveland, Ohio, 2001, Online. http://www.reconnectingamerica.org/assets/Uploads/ bestpractice162.pdf

[5] Gibbons, S. \& Machin, S., Valuing Rail Access using Transport Innovations, Centre for Economic Performance, London School of Economics and Political Science, 2004. Online. http://eprints.lse.ac.uk /19989/1/

[6] Drennan, M.P. \& Brecher, C., Does public transit use enhance the economic efficiency of urban areas? The Journal of Transport and Land Use, 5(3), pp. 53-67, 2012.

[7] McIntosh, J., Alternative Funding Mechanisms for Public Transport in Perth: The Potential Role of Value Capture, Curtin University Sustainability Policy Institute, Corview Group and Committee for Perth, 2011. Online. http://www.mcintoshconsulting.com.au/projects/committee -for-perth/

[8] Kemp, A., Mollard, V. \& Wallis, I., Value capture mechanisms to fund transport infrastructure, NZ Transport Agency research report 511, 2013. Online. $\quad$ http://www.nzta.govt.nz/resources/research/reports/511/docs/ $\underline{511 . p d f}$

[9] Smith, J., Gihring, T. \& Litman T., Financing Transit Systems through Value Capture - An Annotated Bibliography, Victoria Transport Policy Institute, 2014. Online. http://www.vtpi.org/smith.pdf

[10] Medda, F., Land value capture finance for transport accessibility: a review. Journal of Transport Geography, 25, pp. 154-161, Elsevier, 2012.

[11] Walters, L. C., Land Value Capture in Policy and Practice. Proc. Of the World Bank Conference on Land and Poverty, Washington, DC, 2012. Online. http://www.landandpoverty.com/agenda/pdfs/paper/walters full paper.pdf

[12] Litman, T., Evaluating Public Transportation Local Funding Options, Journal of Public Transportation, 17(1), ISSN 1077-291X, 2014.

[13] Doherty, M., Funding public transport development through land value capture programs. Institute for Sustainable Future, 2004. Online. http://www.cooperativeindividualism.org/

[14] Greenleaf Strategies LLC and Parsons Brinckerhoff, Value Capture: Mechanisms, practices \& Prospects for Stimulating economic development and funding commuter rail for the Charlotte North Corridor red line project and the State of North Carolina, 2011. Online. http://redlineregionalrail.org/ 
[15] Committee for Melbourne, Moving Melbourne: A transport funding and financing discussion paper, 2012. Online. http://www.melbourne.org.au/

[16] McIntosh, J., Trubka, R. \& Newman, P. Can value Capture Work in a car dependent city? Willingness to pay for transit access in Perth, Western Australia. Transportation Research Part A, vol. 67, pp. 320-339, 2014.

[17] Vazakidis, A., Investigation of Value Capture Methods for Financing of the Thessaloniki Metro. Diploma Thesis, Supervisor: S. Basbas, Faculty of Rural \& Surveying Engineering, Aristotle University of Thessaloniki, Greece, 2014. 